\title{
Passive Transfer of Antibodies to Shiga Toxin-Producing Escherichia coli O26, 0111 and 0157 Antigens in Neonatal Calves by Feeding Colostrum
}

\author{
Dyah Ayu WIDIASIH ${ }^{1,2)}$, Ibuki MATSUDA ${ }^{1)}$, Katsuhiko OMOE ${ }^{1)}$, Dong-Liang HU' ${ }^{1)}$, Shunji SUGI' ${ }^{3)}$ and \\ Kunihiro SHINAGAWA ${ }^{1) *}$ \\ ${ }^{1)}$ Laboratory of Veterinary Microbiology, Department of Veterinary Medicine, Faculty of Agriculture, Iwate University, 3-18-8 Ueda, \\ Morioka, Iwate 020-0066, Japan, ${ }^{2}$ Department of Veterinary Public Health, Faculty of Veterinary Medicine, Gadjah Mada University, Jl. \\ Agro Karang Malang, Yogyakarta 55281, Indonesia and ${ }^{3}$ Laboratory of Veterinary Microbiology, Department of Veterinary Science, \\ Graduate School of Agriculture and Biological Sciences, Osaka Prefecture University, Sakai, Osaka 599-8531, Japan
}

(Received 12 May 2003/Accepted 8 October 2003)

ABSTRACT. To study whether or not passive immunity of neonatal calves against Shiga toxin-producing Escherichia coli (STEC) O26, O111, and $\mathrm{O} 157$ was obtained by colostrum administration, serum antibodies in calves after the feeding were determined by enzymelinked immunosorbent assay (ELISA) in comparison with antibodies in colostrum and sera from donor dams. The highest antibody titers to STEC in colostrum from dams were detected soon after parturition. The antibody titers were found to be elevated in sera of $n$ eonatal calves (4-9 hr after birth) orally administered with colostrum with high antibody titers, suggesting that passive immunity of neonatal calves to STEC infection may be obtained by feeding colostrum. These results suggest that colostrum administration to neonatal calves may play an important role in elevating serum antibodies against STEC in neonatal calves.

KEY WORDS: calf, colostrum, STEC.

J. Vet. Med. Sci. 66(2): 213-215, 2004

Shiga toxin-producing Escherichia coli (STEC) has been recognized as an etiological agent of an infectious disease in animals and humans. STEC infections are major public health threats because of serious and potentially life-threatening illnesses [10]. Shiga toxin-producing Escherichia coli (STEC) serogroup O157:H7 caused serious outbreaks of food poisoning in Japan in 1996 [6, 7]. Although food poisoning caused by STEC is a serious problem, the source and route of STEC infection have not yet been fully understood in Japan. STEC has often been isolated from rectal contents of beef and dairy cattle [3, 11, 14]; cattle is supposed to be one of STEC reservoirs at the present time. It may be important, therefore, to reduce STEC infections in cattle for prevention of food poisoning caused by STEC. The importance of colostrum consumption by calves soon after birth in relation to disease resistance has already been reported $[1,4,5]$. Our preliminary study on a few calves with STEC infection also indicates that STEC could not be easily isolated from calves with high titers of serum antibodies. However, little is known about bovine passive immunity to STEC infection, although neonatal calves are susceptible to intestinal damages induced by STEC. Therefore, attempts were made to study whether or not passive immunity of neonatal calves to STEC is obtained by colostrum administration to elevate serum antibodies against STEC.

Holstein calves were regularly inspected day and night to separate neonatal calves from their dams before suckling between September and October in 2000. Ten calves before

\footnotetext{
* Correspondence to: Shinagawa, K., Laboratory of Veterinary Microbiology, Department of Veterinary Medicine, Faculty of Agriculture, Iwate University, 3-18-3 Ueda, Iwate 020-8550, Japan.
}

suckling were allocated randomly and administered $1 \mathrm{~L}$ of colostrum in nipple-bottles 0 (just after birth), 4-9, 16-21, $28-33,52-57$, and $76-81 \mathrm{hr}$ after birth. In all cases, the time of the first colostrum administration was designated as $0 \mathrm{hr}$. For the initial administration, colostrum was collected from one and two donor cows after parturition. After the initial colostrum administrations, the calves were moved to a hutch. After the second colostrum administration, the colostrum from three and four dams that had given birth neonatal calves investigated in this study were pooled, frozen, thawed rapidly in warm water, and fed to the neonatal calves. Calves were fed $1 \mathrm{~L}$ of colostrum as soon as possible after birth and again $12 \mathrm{hr}$ later. Following the second feeding, calves were fed $1 \mathrm{~L}$ of second and third milked colostrum from the dam. The general health of the calves was monitored daily.

Blood samples were taken from six cows and six calves. The calves were bled 10 min after colostrum administration. Each of blood samples was collected from the jugular vein and left to clot at room temperature. Sera were separated by centrifugation at $3000-\times \mathrm{g}$ for $15 \mathrm{~min}$ and frozen $\left(-20^{\circ} \mathrm{C}\right)$. Antibodies to STEC were determined by ELISA by using lipopolysaccharides (LPS) as antigens for serotypes O26 and O111 (Sigma Chemical Co., St. Louis, Mo, U.S.A.) and serotype O157 (Denka Seiken, Tokyo, Japan) of STEC. Briefly, wells of 96-well ELISA plate were each coated with $50 \mu l$ of LPS $(10 \mu \mathrm{g} / \mathrm{ml})$ in $0.05 \mathrm{M}$ carbonate buffer ( $\mathrm{pH} 9.6)$ at $37^{\circ} \mathrm{C}$ for $2 \mathrm{hr}$. Then uncoupled binding sites in the wells were blocked with $0.01 \mathrm{M}$ phosphate buffered saline, $\mathrm{pH} 7.2$ containing $0.05 \%$ Tween 20 (PBS) and $0.5 \%$ bovine serum albumin (BSA) (Sigma). After washing the plate, $50 \mu \mathrm{l}$ of 200-fold diluted serum or colostrum was added to each well and the plate was incubated at $37^{\circ} \mathrm{C}$ for $1 \mathrm{hr}$. After washing, 


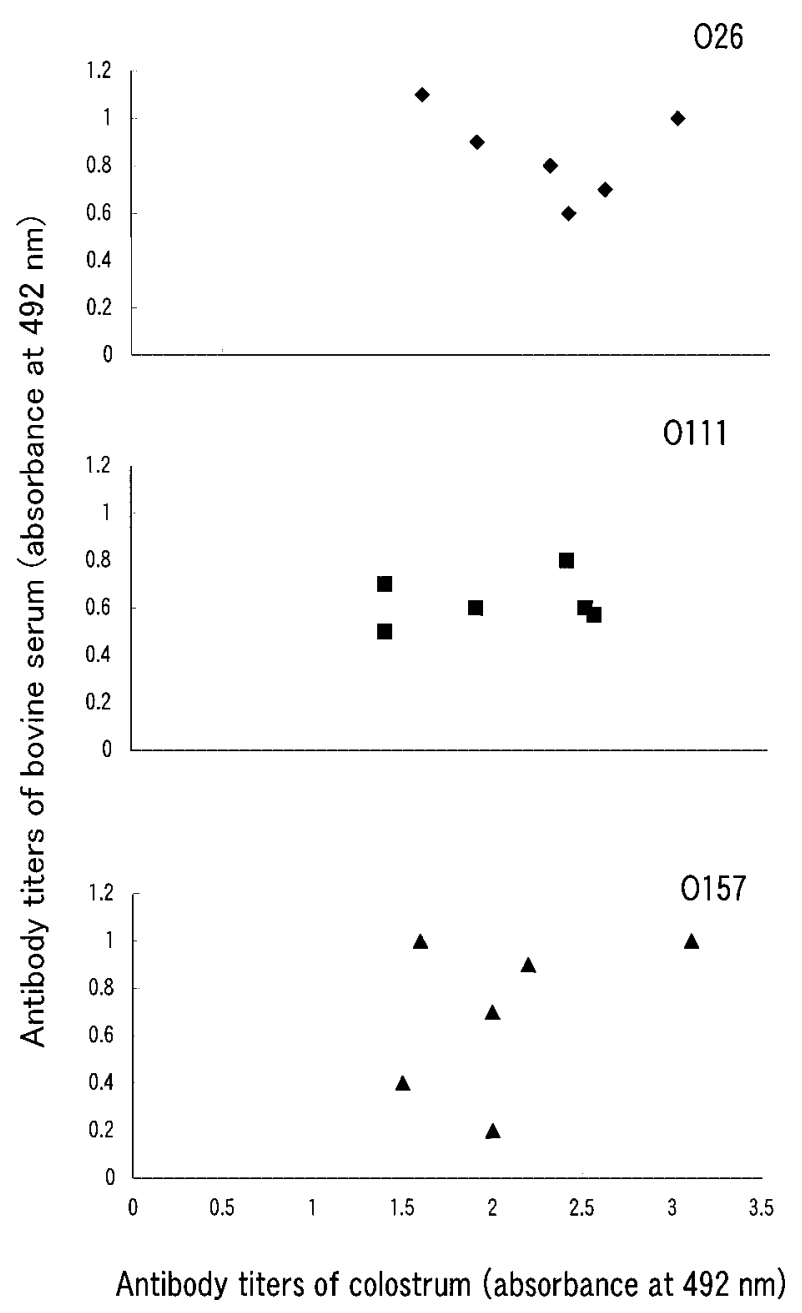

Fig. 1. Antibody titers to STEC O26, O111, and O157 of serum and colostrum of donor dams.

$50 \mu l$ of 1,000-fold diluted horseradish peroxidase-conjugated sheep anti-bovine immunoglobulin G (Bethyl, Lab. Montgomery, Texas) in PBS containing $0.5 \%$ BSA was added to the well. The plate was incubated at $37^{\circ} \mathrm{C}$ for $1 \mathrm{hr}$. After washing, $50 \mu l$ of the substrate solution containing ophenylenediamine (Wako Pure Chemical Industries, Co. Osaka, Japan) and $\mathrm{H}_{2} \mathrm{O}_{2}$ was added to each well for color development. In $20 \mathrm{~min}$ later, the reaction was terminated by addition of $50 \mu \mathrm{l}$ of $2 \mathrm{~N} \mathrm{H}_{2} \mathrm{SO}_{4}$. The reaction (developed color) was determined at $492 \mathrm{~nm}$ in an ELISA plate reader (Bio-Rad, Laboratories, Richmond, Calif). The antibody titers of serum and colostrum were expressed in absorbance at $492 \mathrm{~nm}$.

To determine the antibody titers in serum and colostrum of donor cows (dams), colostrum and sera were obtained from 6 Holstein cows within $24 \mathrm{hr}$ after parturition. The antibody titers of the sera were plotted against those in the corresponding colostrum (Fig. 1). The antibody titers to STEC 0157 of all of the colostrum samples were found to

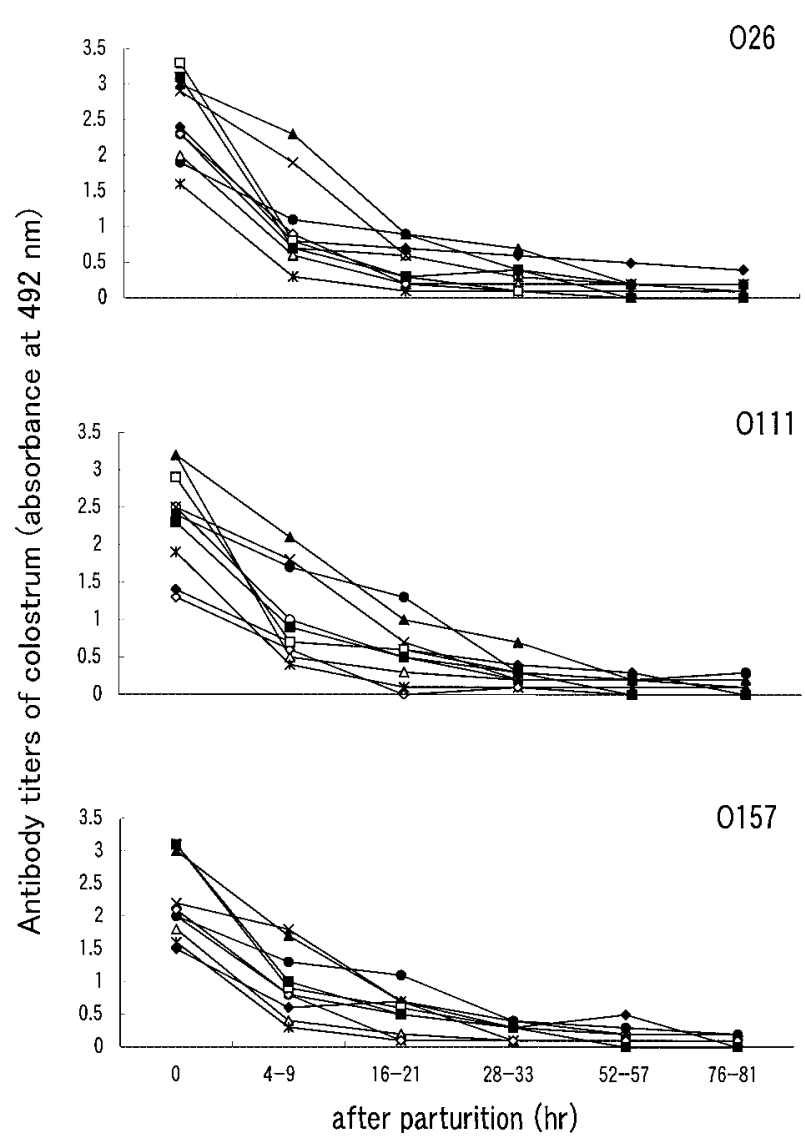

Fig. 2. Antibody titers to STEC O26, O111 and O157 of colostrum from donor dams after parturition. Symbols indicate the dam's numbers tested: $-\checkmark-692,-\bigcirc^{-720,}-\boldsymbol{\Delta}^{-} 724,-\boldsymbol{O}^{-759}$,

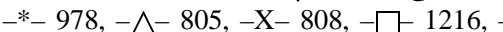
1830 and 1987.

be higher (absorbance: $>1.5$ ) than the corresponding sera as shown in Fig. 1. Similar results were also obtained in the antibody titers to STEC O26 and O111 (Fig. 1). These findings suggest that the antibody titer of colostrum of the dams is higher than that in the sera after parturition.

To determine antibodies of dams to STEC O26, O111 and O157 after parturition, colostrum samples were collected from 10 Holsteins cows (No. 692, 720, 724, 759, 798, 805, $808,1216,1830$ and 1987) in 0, 4-9, 16-21, 28-33, 52-57 and 76-81 hr. As shown in Fig. 2, the highest antibody titer was obtained in the colostrum collected from the cows soon after parturition. After then, antibody titers of colostrum rapidly decreased between 4-9 and 16-21 hr after parturition (Fig. 2). The antibodies were not detected 76-81 hr after parturition (Fig. 2). These findings confirm the previous reports $[1,2,5,8,9,12,13]$ that colostrum collected from cows soon after parturition contained the highest antibody titers against microorganism.

To assess whether or not passive immunity is obtained through colostrum feeding, colostrum was fed to neonatal calves. Before (just after birth) and after feeding, sera were 


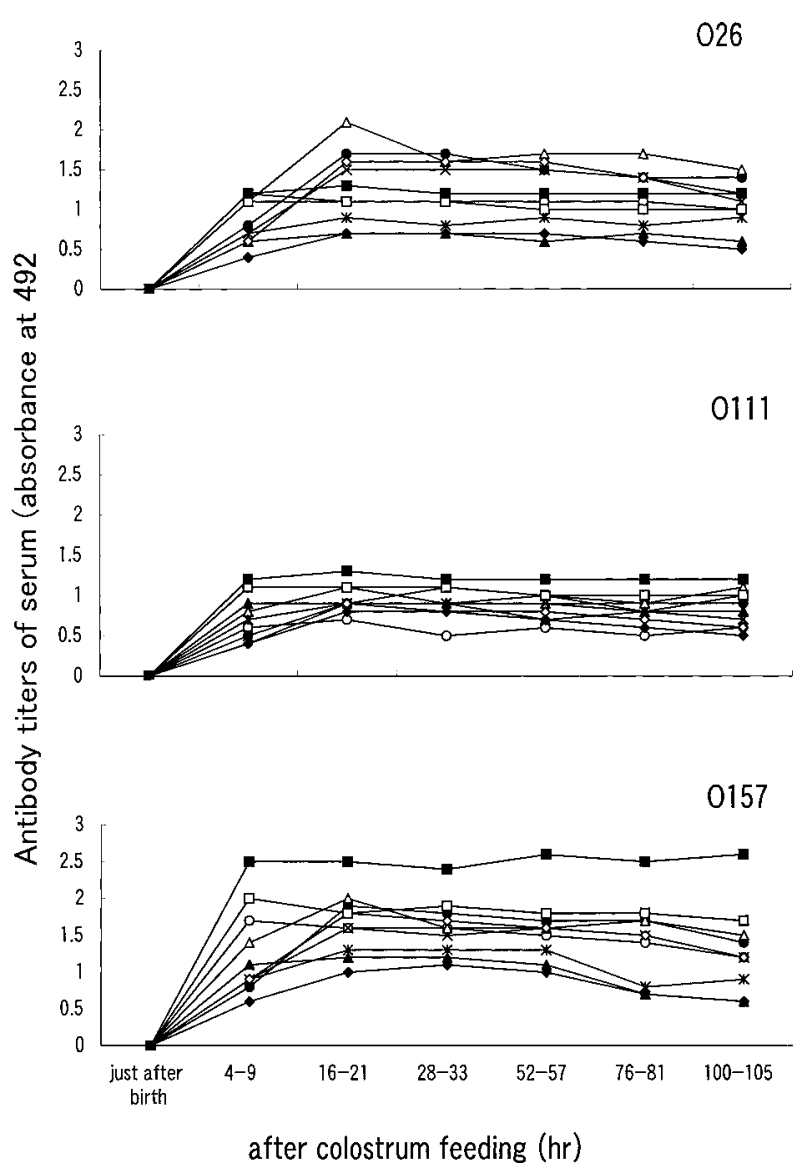

Fig. 3. Antibody titers to STEC O26, O111, O157 of serum of newborn calves after colostrum feeding. Symbols indicate calve's numbers tested. $-\mathrm{O}-430,692$; twin birth calf $\left(-\mathrm{X}_{-}\right.$ Black, $\diamond-$ White $),-755, \triangle-768 \square-12(-1831$ $-\boldsymbol{\Delta}^{-1901, \text {-*}_{-} 1931 \text { a nd }} 1987$.

collected from 10 neonatal calves (No. 430, 692 Black and White, 755, 768, 1901, 1216, 1830, 1931 and 1987) for antibody determination. As shown in Fig. 3, the antibody titers to STEC of sera from neonatal calves rapidly increased after colostrum administration. The antibody titers reached plateau 4-9 hr after the initial colostrum administration and remained at the same levels for at least 100-105 hr. The fast reaction that showed high titers of antibody to STEC was found $4-9 \mathrm{hr}$ and the slow reaction of antibody titers showed at 28-33 hr after colostrum feeding (Fig. 3). However, no antibodies to STEC were found in sera from some neonatal calves $16-21 \mathrm{hr}$ after the initial colostrum feeding. It might have been caused by failure of transfer of passive immunity in these calves. Antibodies to STEC were not found in sera from these neonatal calves before colostrum administration. The high antibody titers in sera from neonatal calves were also observed after colostrum feeding with high antibody titers (data not shown). These findings are consistent with the previous findings that the antibodies titer was the highest in the colostrum at the first milking after parturition and decreased in the colostrum at subsequent milking (Fig. 2).

From the present findings, colostrum administration is effective to elevate the serum antibody titers to STEC of neonatal calves, suggesting that it might protect neonatal calves against STEC infections. To verify this, more detailed studies will be needed in future.

\section{REFERENCES}

1. Aldridge, B. M., Mc. Guirk, S. M. and Lunn, D. P. 1998. Vet. Immunol. Immunopathol. 62: 51-64.

2. Barret, T. J., Green, J. H., Griffin, P. M., Pavia, A. T., Ostroff, S. M. and Wachsmuth, I. K. 1991. Current Microbiol. 23: 189195.

3. Chapman, P. A., Siddons, C. A., Wright, D. J., Norman, P., Fox, J. and Crick, E. 1993. Epidemiol. Infect. 111: 439-447.

4. Jochims, K., Kaup, F. J., Drommer, W. and Pickel, M. 1994. Res. Vet. Sci. 57: 75-80.

5. Klobasa, K., Goel, M. C. and Werhahn, E. 1998. J. Anim. Sci. 76: 923-926.

6. Michino, H., Araki, K., Minami, S. and Tanaka, K. 1996. Am. J. Epidemiol. 190: 116-121.

7. Ministry of Health, Labor and Welfare. 2001. Infectious Agents Surveillance Report (IASR). 22: 135-136.

8. Quigley, J. D., Martin, K. R., Bemis, D. A., Potgieter, L. N. D., Reinmeyer, C. R., Rohrbach, B. W., Dowlen, H. H. and Lamar, K. C. 1995. J. Dairy Sci. 78: 893-901.

9. Quigley, J. D., Fike, D. L., Egerton, M. N., Drewdry, J. J. and Arthington. 1998. J. Dairy Sci. 81: 1936-1939.

10. Samadpour, M., Kubler, M., Buck, F. C., Depavia, G. A., Mazengia, E., Steward, J., Yang, P. and Alfi, D. 2002. J. Food Prot. 65: 1322-1325.

11. Shinagawa, K., 1997. Jpn. Vet. Med. 50: 237-242 (in Japanese).

12. Swecker, W. S., Jr, Thatcher, C. D., Blodgett, D. J. and Schurig, G. G. 1995. Am. J. Vet. Res. 56: 450-453.

13. Todd, A. G. and Whyte, P. B. D. 1995. Aust. Vet. J. 72: 415417.

14. Wells, J. G., Shipman, D., Greene, K. D., Sowers, E. G., Green, J. H., Cameron, D. N., Downes, F. P., Martin, M. L., Griffin, P. M. and Ostroff, S. M. 1991. J. Clin. Microbiol. 29: 985-989. 